\title{
Confidential
}

\section{Determination of carbohydrate composition of macroalgae}

W.J.J. Huijgen

E.M. Cobussen-Pool B.F. van Egmond J.W. van Hal

May 2017

ECN-B--17-002 


\section{Acknowledgement}

Published in: Bénédicte Charrier, Thomas Wichard, C.R.K. Reddy, Protocols for Macroalgae Research, CRC Press 2018, ISBN 978149879422, pp. 201-212, 2018. 


\section{chapter twelve}

\section{Determination of carbohydrate composition of macroalgae}

Wouter J.J. Huijgen, E.M. Cobussen-Pool, B.F. van Egmond, and J.W. van $\mathrm{Hal}$

\section{Contents}

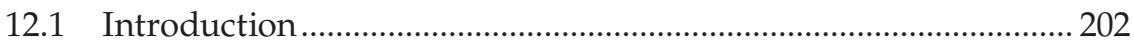

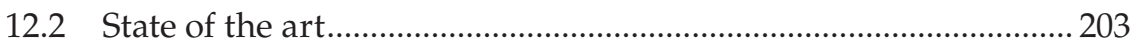

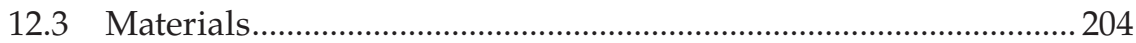

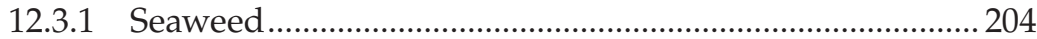

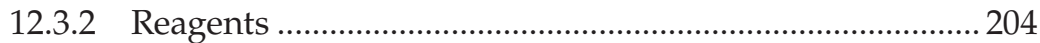

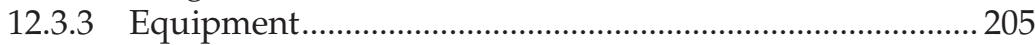

$12.4 \quad$ Experimental procedures .................................................................. 205

12.4.1 Preparation seaweed sample................................................ 206

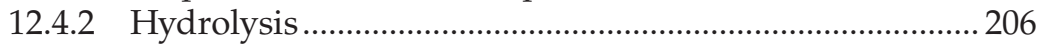

12.4.2.1 Prehydrolysis...................................................... 206

12.4.2.2 Hydrolysis............................................................. 207

12.4.3 Analysis monomeric carbohydrates.................................... 207

12.4.3.1 Sample preparation ............................................ 207

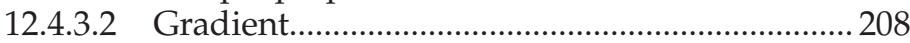

12.4.4 Calculations …………………………………………....... 210

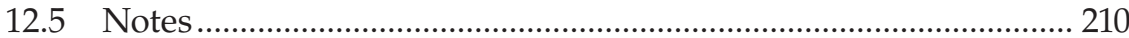

12.5.1 General remarks............................................................... 210

12.5.2 Seaweed hydrolysis ..................................................................211

12.5.3 High-performance anion-exchange chromatography with pulsed amperometric detector.......................................211

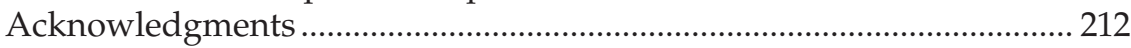

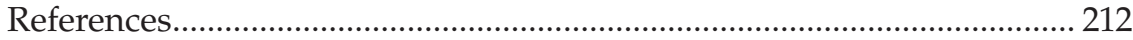




\subsection{Introduction}

Carbohydrates are a major constituent of macroalgae (in addition to minerals and proteins) (Van Hal et al. 2014). In addition, carbohydrates are key target components in the application of macroalgae for production of, for example, biobased chemicals and biofuels (Van Hal et al. 2014). However, a generally accepted protocol for adequate determination of the content of individual carbohydrates is lacking. The EU-H2020 MacroFuels project aims to develop such a protocol.

The carbohydrates that occur in seaweeds vary between the major classes of seaweeds: that is, the brown seaweeds (Phaeophycaea including Kelps), the red seaweeds (Rhodophyta), and the green seaweeds (Chlorophyta). Within the group of red seaweeds, at least three different main structural carbohydrates occur: that is, (1) xylan (e.g., Palmaria palmata), (2) agar (e.g., Gracilaria sp.), and (3) carrageenan (e.g., Chondrus crispus). Table 12.1 gives an overview of carbohydrates reported in the literature for the seaweeds used in our study.

Here, we present a method for determination of the carbohydrate composition of macroalgae based on hydrolysis and subsequent determination of resulting monosaccharides by high-performance anion-exchange chromatography with pulsed amperometric detector (HPAEC-PAD). The presented approach is intended to be uniform for all seaweeds, with optimum hydrolysis conditions that have to be determined for each (class of) seaweed. As an example, the optimum hydrolysis times for three different seaweeds have been identified. This optimization procedure can also be extended to other seaweeds. In addition, a gradient and elution order for the HPAEC-PAD is described that allows determination of the major

Table 12.1 Overview of (structural) carbohydrates present in seaweeds used (Van Hal et al. 2016) (see also Note 12)

\begin{tabular}{|c|c|c|c|}
\hline Seaweed & Laminaria digitata & $\begin{array}{l}\text { Palmaria } \\
\text { palmata }\end{array}$ & Ulva lactuca \\
\hline Seaweed class & Brown & Red & Green \\
\hline $\begin{array}{l}\text { Carbohydrates in } \\
\text { seaweed } \\
\text { (corresponding } \\
\text { monosaccharides } \\
\text { on hydrolysis) }\end{array}$ & $\begin{array}{l}\text { Mannitol } \\
\text { Alginate (mannuronic } \\
\text { and guluronic acid) } \\
\text { Laminarin (glucose) } \\
\text { Cellulose (glucose) } \\
\text { Fucoidan (fucose) }\end{array}$ & $\begin{array}{l}\text { Floridoside } \\
\text { (galactose } \\
\text { and glycerol) } \\
\text { Xylan (xylose) } \\
\text { Cellulose } \\
\text { (glucose) }\end{array}$ & $\begin{array}{l}\text { Ulvan (rhamnose, } \\
\text { xylose, } \\
\text { glucuronic acid, } \\
\text { and iduronic } \\
\text { acid) } \\
\text { Cellulose } \\
\text { (glucose) }\end{array}$ \\
\hline
\end{tabular}


sugar alcohols, reducing sugars, deoxy sugars, and uronic acids occurring in tested seaweeds in a single run.

\subsection{State of the art}

A generally accepted protocol for determination of carbohydrate composition of seaweeds is lacking. However, for other types of biomass, such protocols exist, such as the method for lignocellulosic biomass developed by the U.S. National Renewable Energy Laboratory (NREL). This method is based on two-stage hydrolysis of structural carbohydrate polymers using $\mathrm{H}_{2} \mathrm{SO}_{4}$ and subsequent determination of resulting monosaccharides (Sluiter et al. 2010). In a comparison of different chemical and enzymatic hydrolysis methods, the NREL method has been selected in literature for compositional analysis of brown seaweeds (Manns et al. 2014). In addition to the standard NREL protocol in which second-stage hydrolysis is performed at $121^{\circ} \mathrm{C}$, an alternative protocol with hydrolysis at $100^{\circ} \mathrm{C}$ has been reported in the literature for summative composition analysis of lignocellulosic biomass (TAPPI 2009, Wildschut et al. 2013). This modified approach has been applied in literature to, for example, Ulva lactuca (Van der Wal et al. 2013). Anticipating that more labile carbohydrates such as uronic acids would give a higher recovery at a lower temperature, the starting point for this study was based on this approach, that is, as follows:

- Prehydrolysis: $12 \mathrm{M} \mathrm{H}_{2} \mathrm{SO}_{4}, 30^{\circ} \mathrm{C}, 1 \mathrm{~h}$ (to hydrolyze the polymeric structural carbohydrates into soluble [oligomeric] carbohydrates).

- Hydrolysis: $1.2 \mathrm{M} \mathrm{H}_{2} \mathrm{SO}_{4}, 100^{\circ} \mathrm{C}, 3 \mathrm{~h}$ (to convert oligomeric carbohydrates into monosaccharides).

- Analysis of resulting monomeric carbohydrates by HPAEC-PAD.

The reaction times of both steps have been varied to determine optimum conditions. It was found that prehydrolysis is required to have adequate hydrolysis of structural components such as cellulose and ulvan. Optimum prehydrolysis time determined for all the three seaweeds was 60 min (identical to lignocellulosic biomass).

The optimum hydrolysis time was found to depend on both the seaweed type and specific monosaccharides of interest. For each monosaccharide, a balance between formation and degradation (e.g., to furans), which are both acid catalyzed, needs to be found. Recommended optimum hydrolysis times based on the maximum total carbohydrate response are given in Table 12.2. 
Table 12.2 Optimum hydrolysis times recommended.

\begin{tabular}{llll}
\hline Seaweed & \multicolumn{1}{c}{$\begin{array}{c}\text { Laminaria } \\
\text { digitata }\end{array}$} & $\begin{array}{c}\text { Palmaria } \\
\text { palmata }\end{array}$ & Ulva lactuca \\
\hline $\begin{array}{l}\text { Optimum hydrolysis time (h) } \\
\begin{array}{l}\text { Too short, that is, } \\
\text { underestimation of }\end{array}\end{array}$ & $\begin{array}{l}\text { Mannuronic acid } \\
\text { Glucose }\end{array}$ & $\begin{array}{l}3^{\text {a }} \\
\text { Glucuronic } \\
\text { acid } \\
\text { Rhamnose }\end{array}$ \\
& $\begin{array}{l}\text { (Chemically } \\
\text { bound) mannitol }\end{array}$ & \\
Too long, that is, degradation of & Guluronic acid & Xylose & \\
\hline
\end{tabular}

a Iduronic acid is very sensitive to degradation by hydrolysis. The optimum response of all monosaccharides, including iduronic acid, could not be obtained with a single hydrolysis time.

\subsection{Materials}

\subsubsection{Seaweed}

1. In the case of nondried seaweed, immediately dry it to prevent compositional changes.

i. Optionally, remove large contaminants such as stones and snails.

ii. Cut seaweed, if needed.

iii. Dry at mild conditions, preferably by freeze-drying (alternatively, in a [vacuum] oven at $\leq 50^{\circ} \mathrm{C}$ ).

iv. Check moisture content. Ambient-dry conditions (about 5\%-15\% moisture content, depending on seaweed species) are sufficient.

2. Crush or cut dried seaweed to $<1 \mathrm{~cm}$ and homogenize.

3. Store the dried seaweed in closed containers at ambient temperature until compositional analysis.

\subsubsection{Reagents}

1. $72 \% \mathrm{w} / \mathrm{w}(12 \mathrm{M})$ sulfuric acid (stored at $4^{\circ} \mathrm{C}$ )

2. $\mathrm{BaCO}_{3}$

3. Bromophenol blue indicator $\left(20 \mathrm{mg} \mathrm{L}^{-1}\right)$

4. Standards analysis monomeric carbohydrates:

a. Sugar alcohols:

i. Mannitol

ii. Glycerol

b. Reducing sugars:

i. Glucose

ii. Xylose

iii. Arabinose (might be left out as not detected in seaweeds)

iv. Galactose

v. Fructose (internal standard) 
c. Deoxy sugars:

i. Rhamnose (as L-rhamnose monohydrate)

ii. Fucose

d. Uronic acids:

i. Guluronic acid as the sodium salt (CarboSynth Limited, UK)

ii. Mannuronic acid as the sodium salt (CarboSynth Limited, UK)

iii. Iduronic acid (CarboSynth Limited, UK)

iv. Galacturonic acid

v. Glucuronic acid

\subsubsection{Equipment}

1. Halogen moisture analyzer.

2. $50 \mathrm{~mL}$ centrifuge plastic tubes with a screw cap.

a. Use centrifuge tubes that are heat resistant to maximum operating temperature (i.e., $100^{\circ} \mathrm{C}$ ).

b. Use centrifuge tubes with a cap that are liquid tight at elevated temperature, to prevent leaking while shaking. Centrifuge tubes with a flat screw cap tend to work fine.

3. $10 \mathrm{~mL}$ plastic centrifuge tubes.

4. Water bath set at $30^{\circ} \mathrm{C}$.

5. Water bath set at $100^{\circ} \mathrm{C}$.

6. Centrifuge applicable for $50 \mathrm{~mL}$ centrifuge tubes.

7. Centrifuge applicable for 10-mL centrifuge tubes.

8. HPAEC setup (Dionex, Sunnyvale, CA, USA) consisting of

a. ICS3000 Ion Chromatography System

b. CarboPac PA1 column $(2 \times 250 \mathrm{~mm})$

c. CarboPac guard column $(2 \times 50 \mathrm{~mm})$

d. Pulsed amperometric detector (PAD)

e. Pump 1 (used for gradient over column, $0.25 \mathrm{~mL} / \mathrm{min}$ )

i. Eluent $A$ : Ultrapure water

ii. Eluent B: $0.1 \mathrm{M} \mathrm{NaOH}$ in ultrapure water

iii. Eluent $C$ : $0.1 \mathrm{M} \mathrm{NaOH}$ and $1 \mathrm{M} \mathrm{NaAc}$ in ultrapure water

f. Pump 2 (used for postcolumn addition of $\mathrm{NaOH}, 0.15 \mathrm{~mL} \mathrm{~min}^{-1}$ ) iv. $0.25 \mathrm{M} \mathrm{NaOH}$ in ultrapure water.

\subsection{Experimental procedures}

Determination of the carbohydrate composition of macroalgae consists of the following steps (see also the general Notes 1-5):

- Preparation of seaweed sample.

- Two-stage hydrolysis (to hydrolyze the polymeric structural carbohydrates into monosaccharides). 
- Analysis of resulting monosaccharides by HPAEC-PAD using a gradient that allows determination of the major sugar alcohols, reducing sugars, deoxy sugars, and uronic acids occurring in tested seaweeds in a single run.

\subsubsection{Preparation seaweed sample}

1. Take a representative sample of ambient-dry seaweed from the closed container (see also 3.1.). Use at least about $2 \mathrm{~g}$, but in the case of inhomogeneous sample use a larger amount.

2. Optionally, let seaweed sample equilibrate with ambient humidity overnight. Normally, equilibration takes place during subsequent milling, and this step can be skipped.

3. Mill seaweed sample to $<250 \mu \mathrm{m}$ :
a. Use, for example, a laboratory cutting mill, knife mill, or a vibra- tory disc mill.
b. Avoid heating of the sample while milling (i.e., mill in steps using short milling times).
c. After each milling step, sieve sample over $<250 \mu \mathrm{m}$ and mill part that does not pass again.

4. Transfer seaweed sample quantitatively to a plastic container:

a. Use a brush to get the finer part of the sample off the inside of the mill.

b. Avoid separation of inorganics particles that might be present.

5. Homogenize seaweed sample well by mixing.

6. Take representative subsample and determine moisture content using a moisture analyzer or by drying till constant weight $\left(x_{\text {moisture }}\right)$.

7. Weigh empty $50 \mathrm{~mL}$ centrifuge plastic tube $\left(m_{\text {empty }}\right)$.

8. Weigh in $300 \pm 5 \mathrm{mg}$ of representative subsample in the centrifuge tube $\left(m_{\text {seaweed }}\right)$.

9. Make sure all the sample is at the bottom of the tube.

\subsubsection{Hydrolysis}

\subsubsection{Prehydrolysis}

1. Place tube with the sample in ice water and let it cool down (proper cooling is crucial!).

2. Open the tube and carefully add $3 \mathrm{~mL}$ of prechilled $72 \% \mathrm{w} / \mathrm{w}$ sulfuric acid.

3. Carefully mix the sample with the sulfuric acid using a sealed glass Pasteur pipette. Leave the pipette in the tube.

4. Transfer the open tube to a preheated water bath and incubate for $60 \mathrm{~min}$ at $30^{\circ} \mathrm{C}$ (Note 6). 
5. Mix sample every 10-15 min using the sealed glass Pasteur pipette.

6. After incubation, transfer the tube to ice water to stop the prehydrolysis reaction.

\subsubsection{Hydrolysis}

1. Add demineralized $\mathrm{H}_{2} \mathrm{O}$ to the tube to a final volume of $30 \mathrm{~mL}$. While adding the water, clean the sealed glass Pasteur pipette and take it out.

2. Close the tube with the screw cap and mix well by shaking.

3. Transfer tube, placed in a rack, to a preheated water bath, and incubate at $100^{\circ} \mathrm{C}$ for $180 \mathrm{~min}$ (Laminaria digitata and Ulva lactuca) or 120 min (Palmaria palmata) (Notes 7 and 8).

4. Mix every $45-60$ min by shaking. Be cautious and shake gently as centrifuge tube is hot, and tube and/or screw cap might have become softer at elevated temperature (Note!)

5. After incubation, transfer the tube to ice water to cool down and stop the hydrolysis.

6. Take tube out of ice water, dry the outside, and weigh the tube $\left(m_{\text {final }}\right)$.

7. Centrifuge tube for $5 \mathrm{~min}$ at $2500-3000 \mathrm{~g}$ at $20^{\circ} \mathrm{C}$.

8. Alternatively, the tube can be placed overnight in a refrigerator after initial cooling in ice water to cool down further and allow the residual solids to settle. In general, thus a clear supernatant is obtained, and centrifugation is not needed.

9. Take a sample from the supernatant (Note 9).

10. Store sample in the freezer at $-20^{\circ} \mathrm{C}$ until analysis. The sample should preferably be analyzed within a few weeks but might be kept for substantially longer times.

\subsubsection{Analysis monomeric carbohydrates}

Analysis of monomeric carbohydrates resulting from seaweed hydrolysis as described above can be performed with any adequate technique. However, GC and HPLC techniques are generally not able to adequately distinguish all individual seaweed constituents and require the use of multiple columns and/or derivatization steps. Here, we describe HPAEC, given its ability to separate sugar alcohols, reducing sugars, deoxy sugars, and uronic acids in a single run.

\subsubsection{Sample preparation}

1. Thaw hydrolysate sample.

2. Add $0.2 \mathrm{~mL}$ seaweed hydrolysate to a $10 \mathrm{~mL}$ plastic centrifuge tube.

3. Add $4.8 \mathrm{~mL} 20 \mathrm{mg} \mathrm{L}^{-1}$ bromophenol blue indicator to the tube. 
4. Neutralize by adding small amounts of $\mathrm{BaCO}_{3}$ (total about $75 \mathrm{mg}$ ) until the solution turns blue while vortexing (final $\mathrm{pH}>4.6, \max 8.2$ ).

5. Centrifuge tube for $30 \mathrm{~min}$ at $2500-3000 \mathrm{~g}$ at $20^{\circ} \mathrm{C}$.

6. Take $1.0 \mathrm{~mL}$ of the clear supernatant and add to a vial.

7. Add $0.5 \mathrm{~mL} 150 \mathrm{ppm}$ fructose as an internal standard to the vial (Note 13).

8. Homogenize the solution and place vial in the autosampler of the HPAEC-PAD.

\subsubsection{Gradient}

After sample injection, while using $15 \mathrm{mM} \mathrm{NaOH}$ as mobile phase, pure water is used first as eluent for successively sugar alcohols, deoxy sugars, and reducing sugars and, subsequently, a gradient of $\mathrm{NaOH}$ and $\mathrm{Na}$ acetate is used as eluent for uronic acids (Notes 10-11).

1. Condition column with $0.1 \mathrm{M} \mathrm{NaOH}$ and 1-M NaAc (100\% eluent C) (Note 10).

2. Condition column with $15 \mathrm{mM} \mathrm{NaOH}\left(85 \%\right.$ eluent $\mathrm{A}\left[\mathrm{H}_{2} \mathrm{O}\right]$ and $15 \%$ eluent B [100 mM NaOH]) (Note 10).

3. Inject sample (injection volume $10 \mu \mathrm{L}$ ).

4. Run gradient as given in Table 12.3.

Table 12.3 HPAEC-PAD multigradient optimized for determination of the major sugar alcohols, deoxy sugars, reducing sugars, and uronic acids occurring in tested seaweeds in a single run (including conditioning for next injection).

\begin{tabular}{lccc}
\hline$t(\mathrm{~min})$ & $\begin{array}{c}\text { Eluent A } \\
\left(\mathrm{H}_{2} \mathrm{O}\right)(\%)\end{array}$ & $\begin{array}{c}\text { Eluent B }(0.1 \mathrm{M} \\
\mathrm{NaOH})(\%)\end{array}$ & $\begin{array}{c}\text { Eluent C }(0.1 \mathrm{M} \mathrm{NaOH} \\
\text { and } 1 \mathrm{M} \mathrm{NaAc})(\%)\end{array}$ \\
\hline 0 & 85 & 15 & 0 \\
0 & 85 & 15 & 0 \\
2 & 85 & 15 & 0 \\
2 & 100 & 0 & 0 \\
12.5 & 100 & 0 & 0 \\
17 & 85 & 15 & 0 \\
17.5 & 73 & 16 & 11 \\
29.5 & 45 & 40 & 15 \\
30 & 0 & 0 & 100 \\
35 & 0 & 0 & 0 \\
35.5 & 85 & 15 & 0 \\
48 & 85 & 15 &
\end{tabular}




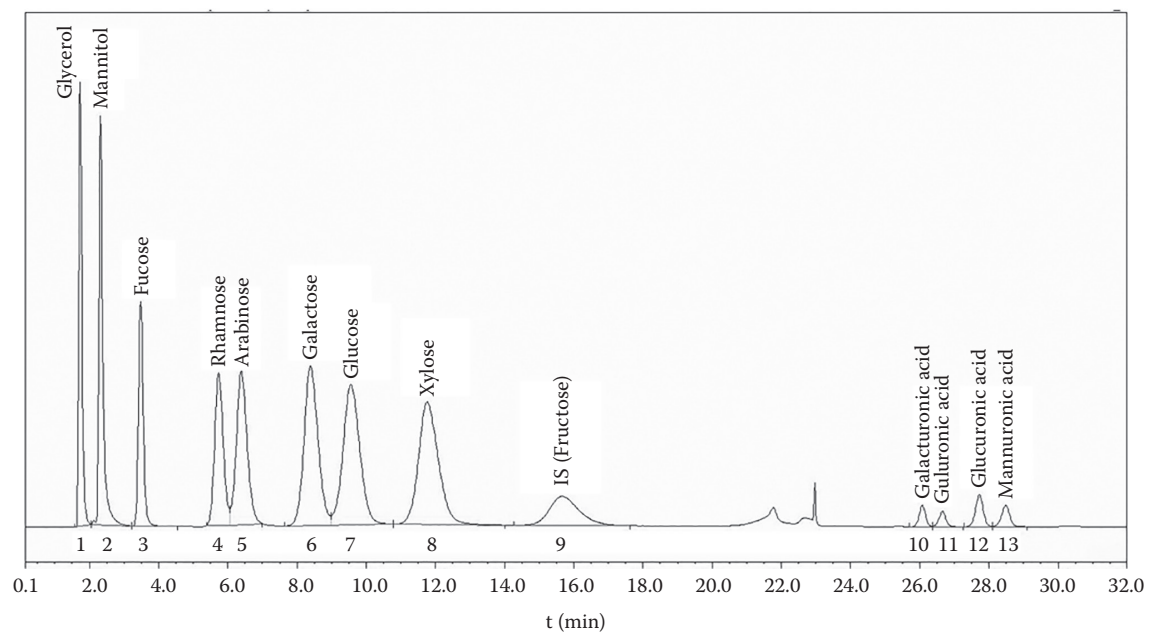

Figure 12.1 HPAEC-PAD chromatograph of a mixture of standards (excluding iduronic acid).

Figure 12.1 shows the HPAEC chromatograph of a mixture of standards and the gradient applied. Table 12.4 gives the elution order of components and the indicative retention times.

For component labeling, see Table 12.4.

Table 12.4 Elution order and indicative retention times of the components (Note 14).

\begin{tabular}{rlr}
\hline$\#$ & Component & $t(\mathrm{~min})$ \\
\hline 1 & Glycerol & 1.7 \\
2 & Mannitol & 2.3 \\
3 & Fucose & 3.5 \\
4 & Rhamnose & 5.7 \\
5 & Arabinose & 6.4 \\
6 & Galactose & 8.4 \\
7 & Glucose & 9.6 \\
8 & Xylose & 11.8 \\
9 & Fructose (IS) & 15.7 \\
10 & Galacturonic acid & 26.1 \\
11 & Guluronic acid & 26.7 \\
12 & Glucuronic acid & 27.7 \\
13 & Mannuronic acid & 28.5 \\
14 & Iduronic acid & 31.0 \\
\hline
\end{tabular}




\subsubsection{Calculations}

The content of individual carbohydrates is calculated by

$$
c_{\text {carb }}=\frac{[\mathrm{carb}] \cdot\left(m_{\text {final }}-m_{\text {empty }}\right)}{m_{\text {seaweed }} \cdot\left(1-x_{\text {moisture }}\right)} \cdot 100 \%
$$

where:

$c_{\text {carb }}$ is the content of carbohydrate in seaweed ( $\% \mathrm{w} / \mathrm{w}$ on dry basis).

[carb] is the concentration carbohydrate in hydrolysate as determined by HPAEC-PAD (g/g).

$m_{\text {final }}$ is the weight of centrifuge tube and hydrolysate after two-stage hydrolysis (g).

$m_{\text {empty }}$ is the weight of empty centrifuge tube (g).

$m_{\text {seaweed }}$ is the weight seaweed sample used for hydrolysis $(\mathrm{g})$.

$x_{\text {moisture }}$ is the moisture content of seaweed sample (-).

The carbohydrate content is based on corresponding monosaccharides. Optionally, a molar mass correction to anhydrous monomeric equivalents can be made in case the carbohydrate is known to be part of a polymer.

\subsection{Notes}

\subsubsection{General remarks}

Note 1: Perform compositional analysis at least in duplicate.

Note 2: The summative composition of seaweeds might be further completed by determination of, among others, proteins (e.g., based on total nitrogen) (Safi et al. 2017), phenolic components (Hou et al. 2017), and ash (by calcination of seaweed at $550^{\circ} \mathrm{C}$ ).

Note 3: In a compositional analysis of lignocellulosic biomass, recovery factors are sometimes used to correct for acid degradation of formed monosaccharides (Sluiter et al. 2010). A similar approach might be followed for seaweeds, although it should be realized that (1) the use of recovery factors tends to lead to an overestimation of the content of individual carbohydrates (Whitfield et al. 2016) and (2) uronic acids are more sensitive to acid degradation than reducing sugars. (Moreover, the sensitivity of each uronic acid toward acid degradation differs.)

Note 4: No distinction between different glucans in, for example, Kelps, that is, laminarin and cellulose, can be made with this method. If required, see Chapter 11 by Graiff et al. (2017).

Note 5: The presented protocol has not been verified for agarophytes, such as Gracilaria sp., carrageenan-containing Rhodophyta such as 
Chondrus crispus and fucoidan-rich brown seaweeds, such as Fucus $s p$. One can use the optimization procedure described to adapt the protocol for the desired seaweed.

\subsubsection{Seaweed hydrolysis}

Note 6: For Palmaria palmata, the prehydrolysis time might be shortened to $30 \mathrm{~min}$.

Note 7: To prevent excessive boiling during the hydrolysis step, which tends to disturb the centrifuge tubes in the rack, the water bath can best be set at $99.5^{\circ} \mathrm{C}-99.8^{\circ} \mathrm{C}$.

Note 8: To prevent pressure built-up during the hydrolysis step, the screw cap of the centrifuge tube might be slightly loosened before the tube is placed in the water bath.

Note 9: Optionally, the dry weight of the solid residue remaining after two-stage hydrolysis might be determined, after washing, to verify the completeness of the liquefaction.

\subsubsection{High-performance anion-exchange chromatography with pulsed amperometric detector}

Note 10: Adequate conditioning of the column is crucial for proper analysis and stable retention times.

Note 11: Calibration standards are perishable.

Open solutions of calibration standards as least as possible to reduce the risk of microbiological contamination.

Store calibration standards adequately.

Check calibration curves using an independent standard.

Note 12: In case other sugar alcohols than only mannitol and glycerol are present in the hydrolysate, separation of individual sugar alcohols over the CarboPac PA1 column might be insufficient. In that case, additional analysis of the hydrolysate with another analytical method is recommended such as HPAEC-PAD using a CarboPac MA1 column.

Note 13: In (tested) seaweeds, as far as known, no fructose is present. However, the absence of fructose should always be verified for each type of seaweed by HPAEC-PAD analysis of its hydrolysate without the addition of an internal standard. As an alternative to fructose, for example, ribose might be used as internal standard. The retention time of ribose is slightly longer than that of fructose.

Note 14: Mannose cannot be separated adequately from xylose with the presented HPAEC-PAD protocol. Please be aware when applying this protocol to other types of biomass such as nonmarine aquatic plants such as Azolla and water hyacinth. In seaweeds, as far as known, no mannose is present. 


\section{Acknowledgments}

The authors thank Mark Smit for his contribution to the experimental work and Arjan Smit for his ideas and input. The current chapter is part of the MacroFuels project. This project has received funding from the European Union's Horizon 2020 research and innovation program under grant agreement No 654010.

\section{References}

Graiff, A., W. Ruth, and U. Karsten. 2017. Identification and quantification of laminarin in brown algae. In Protocols for Macroalgae Research, B. Charrier, T. Wichard, and C. R. K. Reddy, (Eds.), Chapter 11. Boca Raton, FL: CRC Taylor \& Francis.

Hou, X., R. Neerup, and A. B. Bjerre 2017. Total phenol content and antioxidant capacity analysis of seaweed biomass. In Biotechnology Protocols for Macroalgae Research, B. Charrier, T. Wichard, and C. R. K. Reddy (Ed.), Chapter 15. Boca Raton, FL: CRC Taylor \& Francis.

Manns, D., A. L. Deutschle, B. Saake, and A. S. Meyer 2014. Methodology for quantitative determination of the carbohydrate composition of brown seaweeds (Laminariaceae). RSC Advances 4:25736-25746.

Safi, C., J. van Leeuwen, Y. Telleman, N. Engelen-Smit, L. van den Broek, and P. Harmsen 2017. Quantification of proteins in seaweeds. In Biotechnology Protocols for Macroalgae Research, B. Charrier, T. Wichard, and C. R. K. Reddy (Eds.), Chapter 13. Boca Raton, FL: CRC Taylor \& Francis.

Sluiter, J. B., R. O. Ruiz, C. J. Scarlata, A. D. Sluiter, and D. W. Templeton 2010. Compositional analysis of lignocellulosic feedstocks. 1. Review and description of methods. J. Agric. Food Chem. 58:9043-9053.

TAPPI (Technical Association of the Pulp and Paper Industry) 2009. Standard test methods. http://www.tappi.org. Norcross, GA.

Van der Wal, H., B. L. H. M. Sperber, B. Houweling-Tan, R. R. C. Bakker, W. Brandenburg, and A. M. López-Contreras 2013. Production of acetone, butanol, and ethanol from biomass of the green seaweed Ulva lactuca. Bioresour. Technol. 128:431-437.

Van Hal, J. W., A. B. Bjerre, A. M. López-Contreras, M. Stanley, G. O. Hreggvidsson, and W. J. J. Huijgen 2016. Carbohydrate analysis of seaweed in the biorefinery to chemicals and fuel context. Paper Presented at the International Seaweed Symposium, Copenhagen, Denmark.

Van Hal, J. W., W. J. J. Huijgen, and A.M. López-Contreras 2014. Opportunities and challenges for seaweed in the biobased economy. Trends Biotechnol. 32:231-233.

Whitfield, M. B., M. S. Chinn, and M. W. Veal 2016. Improvement of acid hydrolysis procedures for the composition analysis of herbaceous biomass. Ener. Fuels 30:8260-8269.

Wildschut, J., A. T. Smit, J. H. Reith, and W. J. J. Huijgen 2013. Ethanol-based organosolv fractionation of wheat straw for the production of lignin and enzymatically digestible cellulose. Bioresour. Technol.135:58-66. 
